\title{
Transporte ascendente da mistura formulada de imazethapyr e imazapic em resposta à profundidade do lençol freático
}

\author{
Upward movement of the formulated mixture of imazethapyr and imazapic \\ in response to height of the water table
}

\author{
Angela Da Cas Bundt ${ }^{\mathrm{I}^{*}}$ Luis Antonio de Avila ${ }^{\mathrm{I}}$ Jesus Juares de Oliveira Pinto \\ Tiago Torres dos Santos ${ }^{I}$ Dirceu Agostinetto ${ }^{\mathrm{I}}$ Karen Martins ${ }^{\mathrm{I}}$
}

\section{RESUMO}

Os herbicidas usados na cultura do arroz Clearfield ${ }^{\circledR}$ podem persistir no ambiente e causar danos no arroz não tolerante, cultivado em sucessão. Esse dano pode ser de intensidade variável, dependendo, dentre outros fatores, do movimento ascendente do herbicida para região de absorção do sistema radicular das plantas. O objetivo desta pesquisa foi verificar o efeito da altura do lençol freático no movimento ascendente do herbicida composto pela mistura formulada de imazethapyr e imazapic. Para isso, foram coletados lisímetros de solo com auxílio de tubos de PVC $(15 \times 30 \mathrm{~cm})$. O herbicida foi aplicado na superfície inferior dos lisímetros, onde foram simulados diferentes profundidades do lençol freático $(0,5,10,15$ e $25 \mathrm{~cm}$ da superfície do solo). Os lisímetros permaneceram nessa condição por período de 150 dias, quando foram cortados longitudinalmente, seccionados em porções de $5 \mathrm{~cm}(0-5$ a $25-30 \mathrm{~cm})$ e realizado bioensaio com a cultivar de arroz não tolerante, IRGA 417. Com os resultados obtidos, foi possível concluir que ocorre movimento ascendente da mistura formulada dos herbicidas imazethapyr e imazapic ao longo do perfil do solo de várzea durante o período da entressafra do arroz irrigado, sendo este maior quando o lençol freático está localizado mais próximo da superfície do solo. O movimento ascendente através da diluição do herbicida na solução do solo ocorre por fluxo de massa através do arraste pela água, transportada por capilaridade para zonas mais superficiais do solo.

Palavras-chave: arroz irrigado, efeito residual, herbicida, lixiviação.

\section{ABSTRACT}

The herbicides that use the Clearfield Rice System can persist in the environment and damage non-tolerant rice sowing in rotation. This damage can variable in intensity, depending on, among other factors, of the upward movement of the herbicide to the absorption region of the plant root system. The aim of this research was to verify the effect of the height of the water table in upward movement of the herbicide in intact soil cores. Intact soil cores were collected with PVC tubes $15 \mathrm{~cm}$ in diameter and $30 \mathrm{~cm}$ deep. The herbicide was applied on the bottom of the samples, and it was simulated water table depths $(0,5,10,15$ and $25 \mathrm{~cm}$ of the soil surface). The intact samples remained in this condition for a period of 150 days, when they were cut into $5 \mathrm{~cm}$ slices $(0-5$ a $25-30 \mathrm{~cm})$ and bioassay were performed with the non-tolerant rice cultivar. With the results it was conclude that there is upward movement of the formulated mixture of imazethapyr and imazapic herbicides along the paddy soil profile during the fallow and this transport is greater when the water table is located closer to the soil surface. The upward movement by dilution of the herbicide in the soil solution occurs by mass flow through the water transported by capillarity to superficial sites of soil.

Key words: rice, residual effect, herbicide, leaching.

\section{INTRODUÇÃO}

O Sistema Clearfield ${ }^{\circledR}$ de produção de arroz irrigado consiste na utilização de cultivar tolerante aos herbicidas do grupo químico das imidazolinonas e no uso de herbicidas desse grupo, dentre eles, a mistura formulada de imazethapyr e imazapic $\left(75+25\right.$ g i.a. $\left.L^{-1}\right)$. Esses herbicidas caracterizam-se por serem persistentes no solo graças à baixa degradação em condição de anaerobiose (MANGELS, 1991; KRAEMER et al., 2009), condição comum ao longo do cultivo do arroz irrigado da entressafra. A presença desses herbicidas no solo pode causar uma série de problemas para culturas suscetíveis semeadas em sucessão ao arroz irrigado, ou ao próprio arroz não tolerante, semeado em rotação (VILLA et al., 2006;

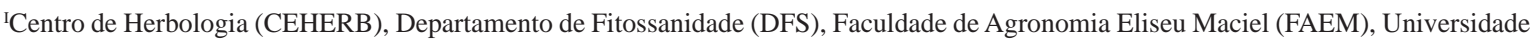
Federal de Pelotas (UFPel), CP 354, 96010-900, Pelotas, RS, Brasil. E-mail: angelabundt@gmail.com. *Autor para correspondência. 
KRAEMER, 2009; PINTO, et al. 2009a; PINTO, et al., 2009b).

Assim como para a maioria dos herbicidas, o principal mecanismo de dissipação das imidazolinonas no solo é através da degradação microbiana aeróbica (LOUX et al., 1989). Contudo, a dinâmica desses herbicidas também é afetada por propriedades do solo, como pH (LOUX \& REESE, 1993), teor de matéria orgânica (STOUGAARD et al., 1990), textura (LOUX \& REESE, 1993) e umidade do solo (BAUGHMAN \& SHAW, 1996).

Um aspecto importante na dinâmica das imidazolinonas é a mobilidade ao longo do perfil do solo, devido às características físico-químicas, como baixo coeficiente de adsorção e alta solubilidade em água. A movimentação de um herbicida no solo pode ocorrer em qualquer direção, dependendo do sentido do fluxo de água (JAVARONI et al., 1999). Contudo, a direção mais comum que o herbicida pode ser transportado é a descendente pela ocorrência de grandes volumes de água de percolação em condições de cultivo de arroz irrigado. Esse processo interfere no comportamento do herbicida no solo, podendo torná-lo mais ou menos eficiente, influenciando diretamente no seu desempenho no controle de plantas daninhas (OLIVEIRA et al., 2001), além de diminuir a velocidade de sua degradação, aumentando assim o efeito residual.

Estudos mostram que as imidazolinonas possuem pouca mobilidade horizontal (TU et al., 2004), porém, verticalmente, de 80 a $90 \%$ do herbicida aplicado pode se concentrar na camada de 10 a $20 \mathrm{~cm}$ de profundidade no perfil do solo, podendo permanecer nesse local por longos períodos (MANGELS, 1991; LOUX \& REESE, 1993). Imazethapyr e imazapic lixiviam rapidamente após uma chuva; mas trabalhos relatam que, durante o processo natural de perda de umidade do solo, o herbicida pode movimentarse ascendentemente, devido ao movimento de fluxo de massa por capilaridade, conduzido pelas correntes de evapotranspiração da água (VANWYK \& REINHARDT, 2001; FIRMINO et al., 2008). De acordo com AVILA et al. (2005), pelo fato de o herbicida solubilizar-se com o aumento da umidade do solo, ele acaba por ter seu movimento ao longo do perfil de acordo com o movimento da água. Estudos realizados com imazethapyr mostram que ele lixivia até $20 \mathrm{~cm}$ em solo de várzea (KRAEMER et al., 2009) e estando em maiores profundidades ocorre diminuição significativa da biodegradação.

O movimento do herbicida durante o cultivo do arroz deve ser descendente graças à pressão hidráulica da lâmina de irrigação, porém, durante a entressafra, quando não há lâmina de água sobre o solo, pode ocorrer o inverso. Dessa forma, o herbicida que estava localizado em profundidade no solo pode passar a mover-se para camadas mais superficiais, juntamente com a água que é perdida por evaporação e/ou evapotranspiração (VANWYK \& REINHARDT, 2001). Esse comportamento torna-se importante para o sistema de cultivo, pois a disponibilidade de herbicidas na solução do solo tem alta correlação com fitotoxicidade em plantas (LEE et al., 2004). Levando-se em consideração que muitas áreas de várzea permanecem com umidade acima da capacidade de campo também durante o inverno, a degradação microbiana também pode ser pequena nesse período. O movimento ascendente do herbicida pode ser ainda mais pronunciado devido às oscilações dos níveis do lençol freático, que, nas áreas de várzea, estão próximos à superfície do solo, podendo carrear o herbicida para locais mais superficiais. Dessa forma, faz-se necessário entender a dinâmica do movimento desses herbicidas no solo em função do nível do lençol freático.

Em vista do exposto, o objetivo do trabalho foi verificar o efeito da altura do lençol freático no movimento ascendente do herbicida composto pela mistura formulada de imazethapyr e imazapic.

\section{MATERIAL E MÉTODOS}

O experimento foi realizado em casa de vegetação pertencente à Faculdade de Agronomia Eliseu Maciel junto a Universidade Federal de Pelotas (FAEM/UFPel), no período compreendido entre abril e novembro de 2009. Este foi conduzido em delineamento inteiramente casualizado com quatro repetições. Os tratamentos consistiram na simulação de diferentes profundidades do lençol freático no solo $(0,5,10,15$ e $25 \mathrm{~cm})$ e diferentes profundidades de corte do lisímetro (0-5, 5-10, 10-15, 15-20, 20-25 e $25-30 \mathrm{~cm})$.

Lisímetros (amostras não deformadas de solo) foram coletados da várzea do Centro Agropecuário da Palma (CAP-FAEM-UFPel), sendo o solo classificado como Planossolo Hidromórfico eutrófico solódico (Unidade de Mapeamento Pelotas), o qual tinha as seguintes características: pHágua(1:1)=5,1; CTC pH7=5,4 cmolc $\mathrm{dm}^{-3}$; Matéria Orgânica=1,2\%; argila=15\%; textura=4. Os lisímetros foram coletados com auxílio de tubos de PVC $(15 \times 30 \mathrm{~cm})$, sendo enterrados no solo até a profundidade de $30 \mathrm{~cm}$ e, logo após, retirados do 
solo de modo que a amostra não deformada ficasse acondicionada dentro do tubo. Na base inferior dos lisímetros, foi aplicado o correspondente a $1 \mathrm{~L} \mathrm{ha}^{-1}$ da mistura formulada de imazethapyr e imazapic $\left(75+25\right.$ g i.a. $\left.\mathrm{L}^{-1}\right)$, com o auxílio de borrifador de água, sendo que o volume do herbicida aplicado foi diluído em 20mL de água destilada. Logo após, a base inferior do tubo foi vedada com uma tampa furada (CAP de PVC) que teve seu interior preenchido com lã de vidro, para permitir que o movimento de água fosse uniforme ao longo do tubo. No interior da tampa, foi acondicionado outro tubo de PVC de 10 e $5 \mathrm{~cm}$ de diâmetro e altura, respectivamente, de modo que esse ficasse inserido no centro da base do lisímetro e permitisse que o movimento ascendente de água fosse concentrado na parte interior do diâmetro do lisímetro (Figura 1).

Após a realização dos procedimentos de vedação da base dos tubos contendo os lisímetros, esses foram alocados em tubos de PVC $(20 \times 40 \mathrm{~cm})$, que também possuíam a base vedada por CAPs de PVC e impermeabilizados com silicone líquido para evitar possíveis perdas de água. No interior desses tubos, foram colocados suportes para permitir que os lisímetros ficassem suspensos dentro do tubo e para que a água tivesse livre acesso a esses. Posteriormente, foram aplicados os tratamentos, que consistiram na simulação de diferentes profundidades do lençol freático, medidas através da borda superior do lisímetro. Para evitar a ocorrência de fluxo preferencial de água pelas paredes do tubo, foi utilizada parafina, que teve por finalidade preencher possíveis espaços vazios que se formaram durante a coleta das amostras de solo, sendo aplicada nas laterais das bases superior e inferior dos monolitos. Durante o período que os lisímetros permaneceram dentro dos tubos com água, foi realizado o controle de plantas daninhas através de arranquio manual. Esse controle teve a finalidade de evitar que estas plantas absorvessem água das camadas mais profundas do solo e carreassem consigo o herbicida.

Essa etapa do experimento foi conduzida durante o período de 150 dias (abril a setembro de 2009), quando foi realizado monitoramento diário da altura da lâmina de água contida nos tubos, mantendo-a estática. Após esse período, os lisímetros foram cortados lateralmente com auxílio de serras e a amostra intacta foi retirada, sendo seccionada em pedaços de $5 \mathrm{~cm}$ de espessura, de modo que o lisímetro ficasse dividido em seis partes iguais (0-5 a $25-30 \mathrm{~cm})$. Cada uma dessas partes foi utilizada para a condução da segunda etapa do experimento, que consistiu de um bioensaio para verificação da presença do herbicida no solo.

Para a realização do bioensaio, foram utilizados potes plásticos com capacidade de $500 \mathrm{~mL}$, onde o solo, pertencente a cada camada de secção do lisímetro, foi destorroado e acondicionado nos copos. Em cada pote, foram semeadas cinco sementes pré-germinadas da

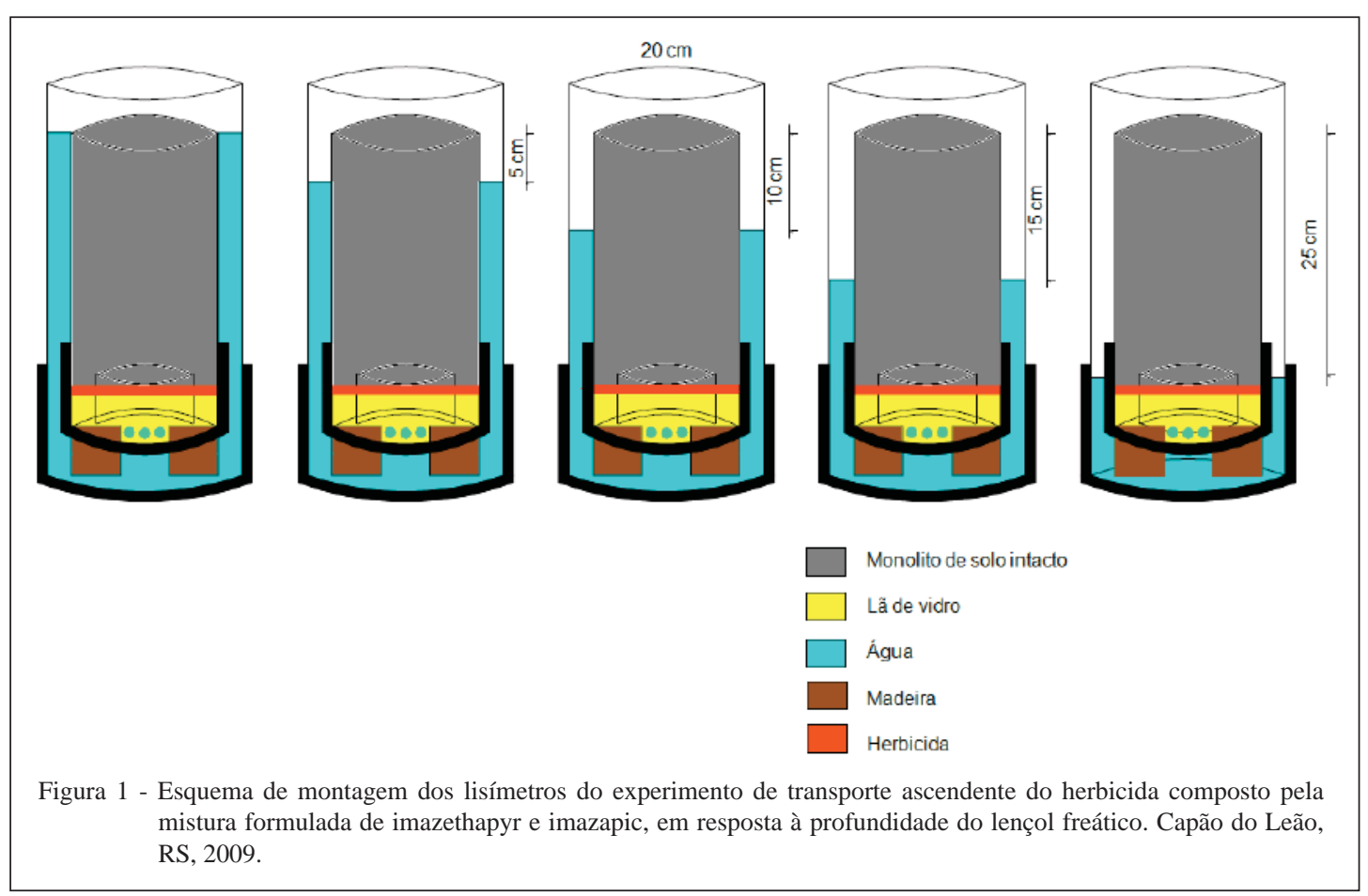

Ciência Rural, v.43, n.9, set, 2013. 
cultivar de arroz irrigado IRGA 417, sendo que, após o estabelecimento das plântulas, foi realizado desbaste, permanecendo três plântulas de arroz por pote. A adubação de base foi realizada dois dias antes da semeadura e consistiu da aplicação do equivalente a $420 \mathrm{~kg} \mathrm{ha}^{-1}$ da formulação 5-2222 (N-P-K). A adubação nitrogenada em cobertura foi aplicada na forma de ureia no estádio V3-V4 (COUNCE et al., 2000), quando foi aplicado o equivalente a $70 \mathrm{~kg} \mathrm{ha}^{-1}$.

As variáveis avaliadas foram fitotoxicidade visual dos herbicidas às plantas de arroz aos 7, 14, 21 e 28DAE (dias após a emergência das plântulas), atribuindo-se valores em percentagem de zero a 100 para ausência de sintomas de fitotoxicidade e morte das plantas, respectivamente; massa da matéria seca (gramas) e estatura da parte aérea (centímetros) das plantas aos 28DAE. Para determinação da massa da matéria seca, a parte aérea das plantas de arroz foi cortada ao nível do solo, sendo submetidas à secagem em estufa de circulação forçada de ar a $60^{\circ} \mathrm{C}$, até obter massa constante para ser pesada.

Os dados foram analisados quanto ao cumprimento das pressuposições do modelo matemático e, então, submetidos aos procedimentos de análise da variância e comparação de médias através do teste Tukey a $5 \%$ de probabilidade de erro.

\section{RESULTADOS E DISCUSSÃO}

Nas plantas de arroz não tolerantes ao herbicida, foram observados sintomas de fitointoxicação aos 7, 14, 21 e 28DAE (Figura 2), os quais foram mais expressivos em maiores profundidades do perfil do solo $(20-30 \mathrm{~cm})$, devido ao fato do herbicida ter sido aplicado na parte inferior do lisímetro. Sinais de fitotoxicidade dos herbicidas nas plantas também foram observados em profundidades superiores, demonstrando o movimento ascendente do herbicida ao longo do perfil, tanto em condições de solo saturado (com lençol freático superficial) quanto em lençol freático profundo ( $25 \mathrm{~cm}$ de profundidade). Esse movimento ascendente, diferentemente do descendente, ocorre de forma mais lenta, por isso convém lembrar que o presente experimento foi conduzido pelo período de 150 dias, tendo por objetivo simular todo o período de entressafra no cultivo de arroz irrigado.

Os herbicidas pertencentes ao grupo químico das imidazolinonas são relativamente móveis, e tal movimento pode ocorrer em diferentes direções ao longo do perfil do solo. GAN et al.
(1994) demonstram haver pouco movimento descendente de imazethapyr em lavouras, sob circunstâncias normais da aplicação, sendo que o maior movimento descendente do herbicida pelo perfil do solo ocorre em circunstâncias de excesso de pluviosidade ou irrigação, como é o caso do arroz irrigado, que, durante o cultivo, recebe a aplicação de grandes volumes de água, podendo variar de 7 a 12mil m (MACHADO et al., 2006). Segundo MCDOWELL et al. (1997), em condições de baixa precipitação, o imazapyr, outro herbicida pertencente ao grupo químico das imidazolinonas, concentra-se na camada superficial, diminuindo consideravelmente sua concentração abaixo de $10 \mathrm{~cm}$. Com altas precipitações, o herbicida atinge maior profundidade, distribuindo-se mais uniformemente nos primeiros $15 \mathrm{~cm}$ do solo. Já FIRMINO e colaboradores (2008) demonstraram que herbicidas pertencentes ao grupo químico das imidazolinonas também possuem movimento vertical ascendente, através do processo de capilaridade.

Entretanto, é possível observar que as maiores fitotoxicidades nas plantas de arroz, além de ocorrer na profundidade de $25-30 \mathrm{~cm}$, foram maiores nos tratamentos em que o lençol freático estava localizado nas maiores profundidades em relação à superfície do solo (Figura 2). Isso é um indicativo de maior concentração dos herbicidas nessa camada. Em contrapartida, foram observados sintomas de fitotoxicidade na profundidade de corte $0-5 \mathrm{~cm}$ nos tratamentos de 10,15 e $25 \mathrm{~cm}$ de profundidade do lençol freático. Esses resultados indicam que pode ter ocorrido efeito hormético do herbicida às plantas de arroz, onde uma pequena quantidade de herbicida presente nessa camada pode ter estimulado o desenvolvimento das plantas. A maior uniformidade de fitointoxicação nas plantas ao longo do perfil do solo foi observada no tratamento em que o lençol freático estava localizado no nível da superfície do solo, sendo essa observada em todas as avaliações. Tal comportamento evidencia o transporte ascendente do herbicida dissolvido em água, pois, por possuir alta solubilidade, torna-se mais disponível na solução do solo em condições de alagamento.

A presença de fitotoxicidade nas plantas cultivadas nas camadas mais superficiais do lisímetro nos tratamentos de maior profundidade do lençol freático $(25 \mathrm{~cm})$ mostra que também houve movimento através do fluxo ascendente de água, pelas perdas por evaporação. Nesse caso, tais percentagens de fitotoxicidade evidenciam que $o$ movimento ascendente do herbicida foi relacionado, 


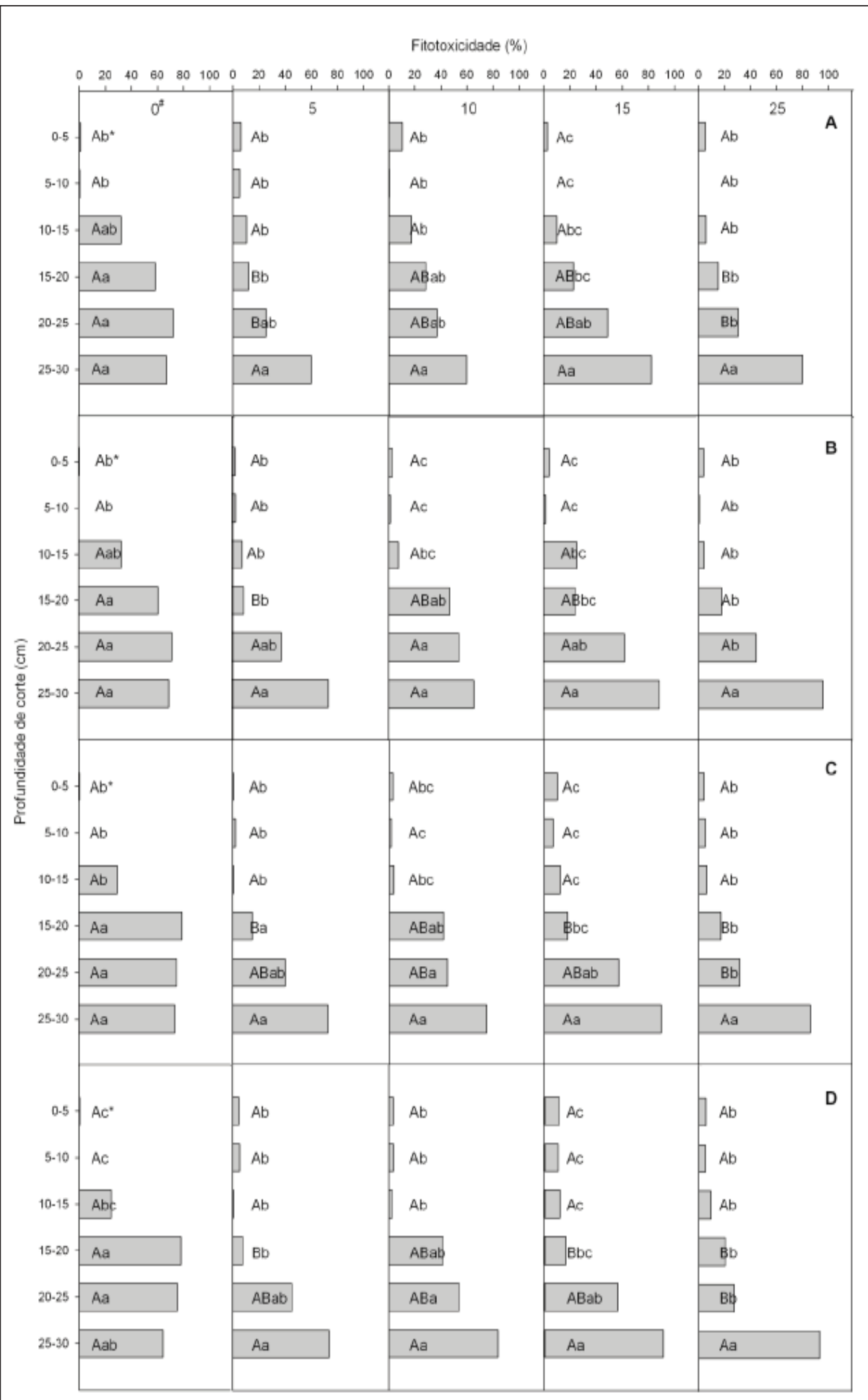

Figura 2 - Estimativa da lixiviação de imazethapyr + imazapic medida através de bioensaio aos 7(A), 14 (B), 21 (C) e 28 (D) dias após a emergência de plantas de arroz irrigado (IRGA 417), cultivadas em solo proveniente de diferentes camadas dos lisímetros, submetidas às diferentes profundidades de localização do lençol freático. *Médias seguidas pela mesma letra maiúscula na linha e minúscula na coluna não diferem entre si pelo teste de Tukey a 5\% de probabilidade de erro. \#Profundidade do lençol freático em relação à superfície do solo. Capão do Leão, RS, 2009. 
provavelmente, com o movimento de água por capilaridade. Em virtude do experimento ser conduzido sem a presença de plantas na superfície do lisímetro, somente foi considerado o efeito das perdas de água por evaporação através da superfície do solo. Em condições de campo, ou seja, com a presença de plantas na superfície do solo, o transporte ascendente do herbicida juntamente com o movimento da água pode ser aumentado, em virtude da corrente evapotranspiratória das plantas e, consequentemente, com o maior movimento de água em direção à superfície do solo.

A partir da análise dos resultados, postulase que o fluxo líquido da água no solo, juntamente com o herbicida, durante a estação de crescimento do arroz irrigado é descendente, devido à pressão hidráulica causada pela inundação, passando-se por período de até 100 dias nessa situação, o que faz com que se concentre em profundidades de 10 a $20 \mathrm{~cm}$ no perfil do solo (MANGELS, 1991; KRAEMER et al., 2009). A proximidade do lençol freático da superfície dos solos de várzea nas condições do Rio Grande do Sul permite que alguns solos permaneçam sob condição de excesso de umidade durante todo o período de entressafra do arroz irrigado (KRAEMER et al., 2009), o que não só dificulta a degradação microbiológica aeróbica do herbicida (MANGELS, 1991) como também permite que, por ser muito solúvel, sofra o processo de dessorção, permanecendo na solução do solo. Na solução do solo, o herbicida pode estar sujeito ao movimento das correntes ascendentes do lençol freático, fazendo com que migre para zonas mais superficiais. O herbicida também pode ser transportado pelas correntes de evapotranspiração durante o processo de perda natural de umidade do solo (VANWYK \& REINHARDT, 2001; FIRMINO et al., 2008).

Com relação à redução de massa da matéria seca da parte aérea das plantas (Figura 3A), não houve diferença significativa entre os tratamentos de profundidade do lençol freático, com exceção dos tratamentos 15 e $25 \mathrm{~cm}$, que apresentaram diferença na profundidade de corte de $20-25 \mathrm{~cm}$. Esse comportamento, assim como o observado para a variável resposta fitotoxicidade, pode ter ocorrido em virtude do efeito hormético do herbicida às plantas de arroz.

Para todas as profundidades do lençol freático foram observadas reduções de matéria seca nas profundidades de corte de 10-15, 15-20, 20-25 e 25-30cm. Do mesmo modo que para a variável fitotoxicidade, a maior homogeneidade nas percentagens de redução de estatura e massa da matéria seca foi observada no tratamento em que o lençol freático ficou localizado mais próximo à superfície, o que evidencia o maior movimento ascendente do herbicida nessa condição. Assim como para as variáveis fitotoxicidade e redução de massa da matéria seca, a variável resposta estatura apresentou maior uniformidade ao longo do perfil do lisímetro no tratamento em que o lençol freático ficou localizado próximo à superfície do solo (Figura 3B).

Portanto, a fitotoxicidade e percentagem de redução de massa da matéria seca e estatura das plantas cultivadas em amostras coletadas mais superficialmente demonstram que houve o movimento ascendente do herbicida ao longo do perfil do solo. Esse comportamento corrobora com resultados encontrados por VANWYK \& REINHARDT (2001) e FIRMINO et al. (2008), que concluíram que além do movimento descendente das imidazolinonas, os herbicidas imazethapyr e imazapyr apresentam movimento ascendente, através do arraste com as correntes ascendentes de água, ou seja, oscilações do lençol freático através do perfil do solo. Assim, o transporte ascendente de herbicidas do grupo químico das imidazolinonas pode ser um dos causadores dos problemas relacionados à persistência do herbicida nos solos arrozeiros do estado do Rio Grande do Sul. A lixiviação desses herbicidas no perfil do solo, para zonas de baixa biodegradação durante a safra do arroz e o posterior lento transporte ascendente desses herbicidas para a superfície do solo durante a entressafra pode ser considerada uma das principais causas da persistência.

\section{CONCLUSÃO}

Existe movimento ascendente da mistura formulada dos herbicidas imazethapyr e imazapic ao longo do perfil do solo de várzea durante o período da entressafra do arroz irrigado, sendo este maior quando o lençol freático está localizado mais próximo da superfície do solo. O movimento ascendente através da diluição do herbicida na solução do solo ocorre por fluxo de massa através do arraste pela água transportada por capilaridade para zonas mais superficiais do solo.

\section{AGRADECIMENTOS}

À Universidade Federal de Pelotas (UFPel), pela disponibilidade de realização do trabalho e à Coordenação de Aperfeiçoamento de Pessoal de Nível Superior (CAPES), pelo apoio financeiro. 


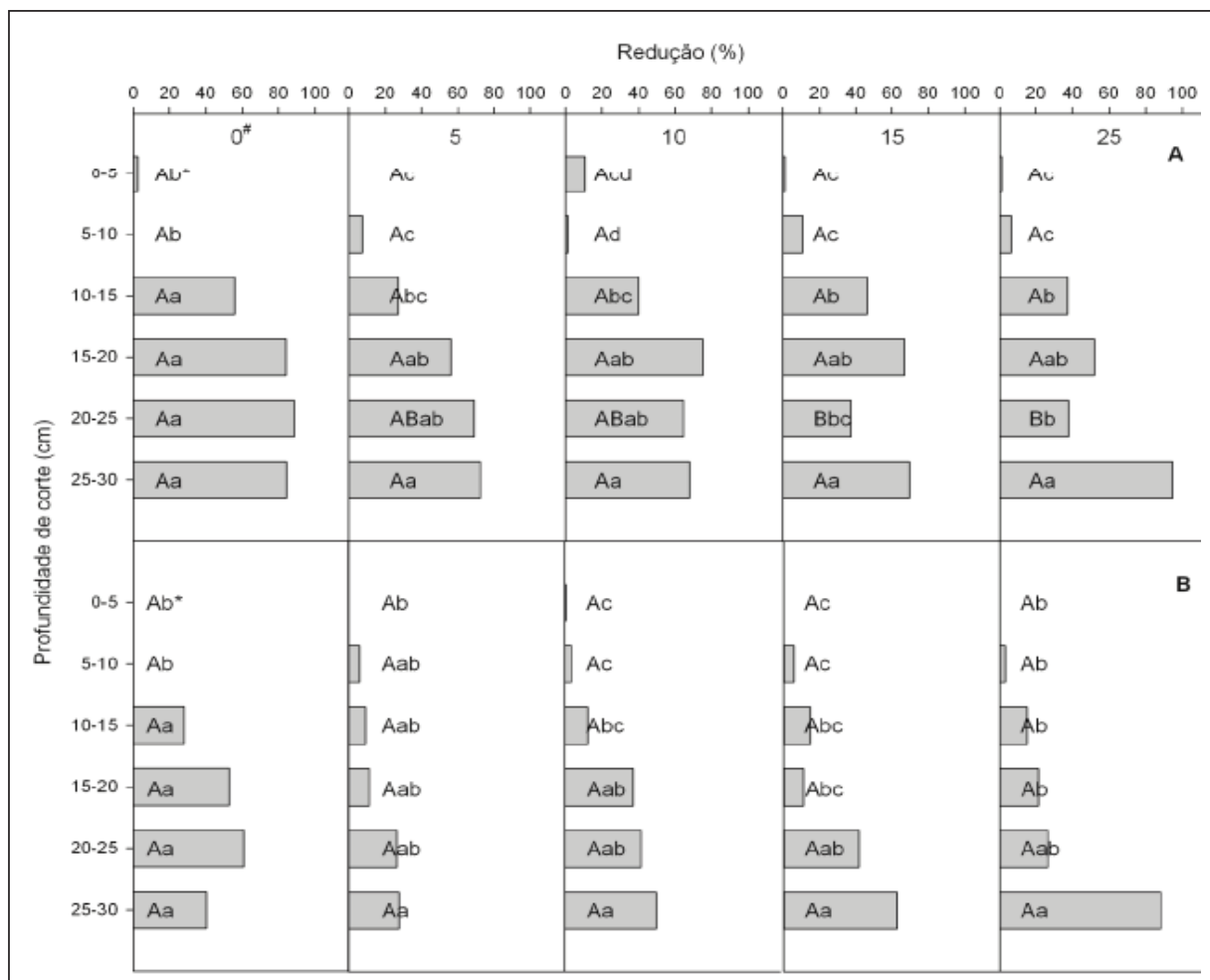

Figura 3 - Estimativa da lixiviação de imazethapyr + imazapic medida através de bioensaio, avaliando a redução de massa da matéria seca (A) e estatura (B) aos 28 dias após a emergência de plantas de arroz irrigado (IRGA 417), cultivadas em solo proveniente de diferentes camadas do lisímetro, submetidas às diferentes profundidades de localização do lençol freático. *Médias seguidas pela mesma letra maiúscula na linha e minúscula na coluna não diferem entre si pelo teste de Tukey a 5\% de probabilidade de erro. \#Profundidade do lençol freático em relação à superfície do solo. Capão do Leão, RS, 2009.

\section{REFERÊNCIAS}

AVILA, L.A. et al. Efeito da umidade do solo na sorção e disponibilidade de imazethapyr em três solos. In: CONGRESSO BRASILEIRO DE ARROZ IRRIGADO, 4.; REUNIÃO DA CULTURA DO ARROZ IRRIGADO, 26., 2005, Santa Maria, RS. Anais... Santa Maria: UFSM, 2005. p.190-193.

BAUGHMAN, T.A.; SHAW, D.R. Effect of wetting/drying cycles on dissipation patterns of bioavailable imazaquin. Weed Science, v.44, n.2, p.380-382, 1996. Disponível em: <http://europepmc. org/abstract/AGR/IND21984334/reload=0; jsessionid=uBmY BeYDzQR05XoG6UAL.34>. Acesso em: 08 fev. 2013. doi: AGR:IND21984334.

COUNCE, P.A. et al. A uniform, objective, and adaptative system for expressing rice development. Crop Science, v.40, n.2, p.436443, 2000.

FIRMINO, L.E. et al. Movimento do herbicida imazapyr no perfil de solos tropicais. Planta Daninha, v.26, n.1, p.223-230, 2008. Disponível em: <http://www.scielo.br/scielo.php?pid=S010083582008000100023\&script=sci_arttext>. Acesso em: 21 nov. 2009. doi:10.1590/S0100-83582008000100023.

GAN, J.M.R. et al. Sorption and desorption of imazethapyr and 5-hydroxyimazethapyr in Minnesota soils. Weed Science, v.42, n.1, p.92-97, 1994. Disponível em: <http://www.jstor.org/ stable/4045549>. Acesso em: 12 dez. 2009.

JAVARONI, R.C. et al. Comportamento dos herbicidas atrazina e alachlor em solo preparado para o cultivo de cana-de-açúcar. Química Nova, v.22, n.1, p.58-65, 1999. Disponível em: <http://www.scielo. br/scielo.php?script=sci_arttext\&pid=S0100-40421999000100012 > . Acesso em: 1 ago. 2009. doi: 10.1590/S0100-40421999000100012.

KRAEMER, A.F. et al. Persistência dos herbicidas imazethapyr e imazapic em solo de várzea sob diferentes sistemas de manejo. Planta Daninha, v.27, n.3, p.581-588, 2009. Disponível em: $<$ http://www.scielo.br/scielo.php?script=sci_pdf\&pid=S0100835 $82009000300020 \& \operatorname{lng}=$ en\&nrm=iso\&tlng=pt $>$. Acesso em: 14 mar. 2010. doi:10.1590/S0100-83582009000300020.

LEE, D.J. et al. Soil characteristics and water potential effects on plant available clomazone in rice. Weed Science, v.52, n.2, p.310-318, 2004. Disponível em: <http://afrsweb.usda.gov/ SP2UserFiles/Place/64022000/Publications/Krutz/Leeetal.2004. pdf>. Acesso em: 12 dez. 2009. doi: 10.1614/WS-03-091R.

LOUX, M.M. et al. Adsorption of imazaquin and imazethapyr on soils, sediments and selected adsorbants. Weed Science, v.37, n.5, p.712-718, 1989. Disponível em: <http://europepmc.org/abstract/ AGR/IND90003909>. Acesso em: 06 fev. 2013. doi: AGR/ IND90003909. 
LOUX, M.M.; REESE, K.D. Effect of soil pH on adsorption and persistence of imazaquin. Weed Science, v.40, n.3, p.490-496, 1993. Disponível em: <http://www.jstor.org/stable/4045295>. Acesso em: 12 out. 2008. doi:10.2134/jeq2002.6130.

MACHADO, S.L.O. et al. Consumo de água e perdas de nutrientes e de sedimentos na água de drenagem inicial de arroz irrigado. Ciencia Rural, v.36, n.1, p.65-71, 2006. Disponível em: <http:// www.scielo.br/pdf/cr/v36n1/a10v36n1.pdf>. Acesso em: $17 \mathrm{fev}$. 2009. doi:10.1590/S0103-84782006000100010.

MCDOWELL, R.W. et al. Dissipation of imazapyr, flumetsulam and thifensulfuron in soil. Weed Research, v.37, n.6, p.381389, 1997. Disponível em: <http://onlinelibrary.wiley.com/doi/ 10.1046/j.1365-3180.1997.d01-73.x/pdf>. Acesso em: 10 jan. 2009. doi:10.1046/j.1365-3180.1997.d01-73.x.

MANGELS, G. Behavior of the imidazolinone herbicides in soil: a review of the literature. In: SHANER, D.L.; O’CONNOR, S.L. (Eds.). The imidazolinone herbicides. Boca Raton: CRC, 1991. p.191-209.

OLIVEIRA, M.F. Comportamento de herbicidas no ambiente. In: OLIVEIRA Jr., R.S.; CONSTANTIN, J. Plantas daninhas e seu manejo. Guaíba: Agropecuária, 2001. p.315-362.

PINTO, J.J.O. et al. Atividade residual de (imazetapir+imazapique) sobre azevém anual (Lolium multiflorum), semeado em sucessão ao arroz irrigado, Sistema Clearfield ${ }^{\circledR}$. Planta Daninha, v.27, n.3, p.609-619, 2009a. Disponível em: <http://www.scielo.br/scielo. php?script=sci_arttext\&pid=S0100-83582009000300023\&lng=en \&nrm=iso\&tlng=PT>. Acesso em: 21 fev. 2013. doi: 10.1590/ S0100-83582009000300023.
PINTO, J.J.O. et al. Atividade residual de (Imazetapir+Imazapique) para sorgo granífero (Sorghum bicolor) semeado em rotação com o arroz irrigado. Planta Daninha, v.27, n. sp, p.1015-1024, 2009b. Disponível em: <http://www.scielo.br/scielo.php?script=sci_ arttext\&pid=S0100-83582009000500015\&lng =en\&nrm=iso \&tlng=pt $>$. Acesso em: 21 fev. 2013. doi: /10.1590/S010083582009000500015 .

STOUGAARD, R.N. et al. Effect of soil type and $\mathrm{pH}$ on adsorption, mobility and efficacy of imazaquin and imazethapyr. Weed Science, v.36, n.1, p.67-73, 1990. Disponível em: <http:// europepmc.org/abstract/AGR/IND90038427>. Acesso em: 05 fev. 2013. doi: AGR:IND90038427.

TU et al. Imazapic. Weed control methods handbook. London: Academic, 2004. Cap.7, p.1-7.

VANWYK, L.J.; REINHARDT, C.F. A bioassay technique detects imazethapyr leaching and liming-dependent activity. Weed Technology, v.15, n.1, p.1-6, 2001. Disponível em: <http://www.bioone.org/doi/pdf/10.1614/0890-037X\%28 2001\%29015\%5B0001\%3AABTDIL\%5D2.0.CO\%3B2>. Acesso em: 6 jul. 2009. doi:10.1614/0890-037X(2001) 015[0001:ABTDIL]2.0.CO;2.

VILLA, S.C.C. et al. Arroz tolerante a imidazolinonas: controle do arroz-vermelho, fluxo gênico e efeito residual do herbicida em culturas sucessoras não-tolerantes. Planta Daninha, v.24, n.4, p.761-768. 2006. Disponível em: <http://www.scielo. br/scielo.php?pid=s0100-83582006000400017\&script $=$ sci_ arttext>. Acesso em: 24 fev. 2013. doi: 10.1590/S0100 83582006000400017 